\title{
Functional rehabilitation of fractured root canal treated posterior tooth: A case report
}

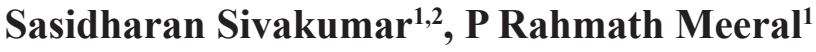 \\ From ${ }^{1} B D S,{ }^{2} M D S$, Department of Public Health Dentistry, Tn. Dr. M.G.R. Medical University, Chennai, Tamil Nadu, India
}

\begin{abstract}
The objective of dentists is to preserve the teeth back to its functional form at any cost based on the requirements and willingness of the patient. This case report emphasizes more on restoring fractured endodontically treated teeth, where the fracture had extended subgingivally deeper to the middle-third of the palatal root segment. Excluding all other restoration methods based on the challenges, the present case was treated using posterior high strength glass ionomer restoration for margin elevation in the radicular segment and miracle mix restoration on the coronal portion of the tooth. Finally, the porcelain fused crown covers the crown completely for further functional usage. The margin is the challenge in this defect management for saving the tooth back to its functional form according to the patient's willingness.
\end{abstract}

Key words: Fractured tooth, Glass ionomer restoration, Margin elevation, Non-vital tooth restoration

$\mathrm{M}$ any dentists have treated patients successfully by means of empiric logical methods that are not supported by sound longitudinal studies. Every new technique needs an initiative without much literature support but with the logical background on consequences that would make it successfully available in the evidence base for future practice. Although in a large epidemiological survey, the long-term functional survival rate of endodontically treated permanent teeth was reported to be $97.1 \%$ after 8 years, coronal and/or radicular tooth fractures continue to remain important reasons for post-endodontic tooth repairs and extractions [1].

Endodontically treated tooth has a greater chance of getting fracture due to coronal destruction during the carious process, fractures, or previous restoration of endodontic technique, resulting in decreased resistance to intraoral forces [2]. In the confined environment of the pulp and dentinal tubules, the presence of free water in the tubules results in increased dentin viscoelasticity and also facilitates the absorption and distribution of forces before the tooth fracture occurs [3]. Hence, the endodontically treated tooth is more prone to fracture due to desiccation and premature loss of fluids from the vital pulps [4].

Most of the literature concerning the restoration of endodontically treated tooth focused more on post-core unit. The post is placed in the root canal, and the core is retained by apical

\section{Access this article online}

Received - 08 September 2020

Initial Review - 24 September 2020

Accepted - 25 September 2020

DOI: $10.32677 / I J C R .2020 . v 06.110 .003$ extension and supports the coronal part that simulates the prepared tooth to hold the definite cast restoration [5-8]. All restorations for endodontically treated pulpless teeth require covering the cusps with a complete cast crown that embraces the tooth structure [2]. This case report describes restoring the posterior non-vitalized tooth without post and core and retentive pins.

\section{CASE REPORT}

A 24-year-old female patient reported with complaints of pain in the root canal-treated right maxillary first molar for the past 10 days. The past dental history reveals that the patient had undergone root canal treatment for the right maxillary first molar a year ago but successively not followed by any prosthetic crowns over it, consequently lead to coronal fracture extending to the root segment. The patient had a non-contributory medical history.

Clinical examination revealed a fractured endodontically treated tooth with a fragment impinging over the periodontium leading to painful symptoms. A thorough inspection revealed that the patient had good oral hygiene, and interpretation of the baseline intraoral periapical radiograph was made at the time when the patient presented (Fig. 1a). The radiograph revealed an unclear view of the defect with an absence of any kind of periapical pathologies (Fig. 1b).

Based on the history, clinical, and radiographic examination, we planned for the restoration of the fractured part with the gingival seat present on the middle-third of the root structure.

Correspondence to: Dr. Sasidharan Sivakumar, No: 5, $12^{\text {th }}$ Cross Street, Mahalakshmi Nagar, Guduvancheri - 603 202, Chennai, Tamil Nadu, India. E-mail: sdmhoralcare@gmail.com

(C) 2020 The Author(s). This open access article is distributed under a Creative Commons Attribution (CC-BY) 4.0 license. 
Clinically, the palatal region of that tooth was anesthetized with $2 \%$ lignocaine with 1:80,000 epinephrine. The fractured segment was removed from the region which revealed that the fracture was located on the mesiopalatal half of the crown structure extending from the middle-third on the palatal and mesial part of the crown superiorly till the middle-third of the root structure inferiorly in an oblique manner (Fig. 2a-c). The palatal flap was elevated to clinically expose the operative site (Fig. 2d).

The gingival seat appears to be present in the middle-third of the palatal root. The local site bleeding was controlled with the lignocaine soaked gauze piece under pressure (Fig. 2e and f). However, the bleeding was not controlled, so limiting composite

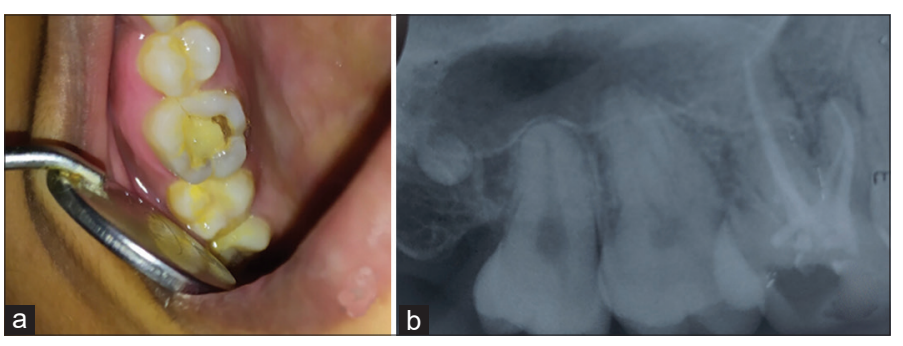

Figure 1: Pre-operative image. (a) Clinical fracture line and (b) radiological view of fractured part core build-up was not possible as it required strict isolation. Then, the gutta-percha cones were flattened accordingly with the remaining tooth structure to avoid seepage of fluids through that gutta-percha pathway into the root canal.

The posterior high strength glass-ionomer cement (GIC) was selected for the build-up in the root surface as it favors the gingival attachment back to its form finally. The miracle mix was avoided for this restoration to avoid any mercury leakage into the tissue spaces subgingivally. The GIC was placed after etching the tooth surface with $37 \%$ orthophosphoric acid for better bonding of GIC with the tooth surface with good marginal adaptation supported with a well-elevated flap for isolation (Fig. $2 \mathrm{~g}$ and $\mathrm{h}$ ).

The retainer was not used as the defect was deeper in this case. Hence, manual shape contouring was chosen as it provides good clinical outcomes in the future. Then, once the margin of the restoration was elevated to a supragingival area, the shape was contoured, and a miracle mix was employed in the superior region for better strength of the restoration for the support of the cast crown covering the tooth completely (Fig. $2 i$ and j).

The tooth was observed for 6 months and inferred with good functional outcomes before placing the crown. Then, the tooth was evaluated for the strength of the restoration and the palatal

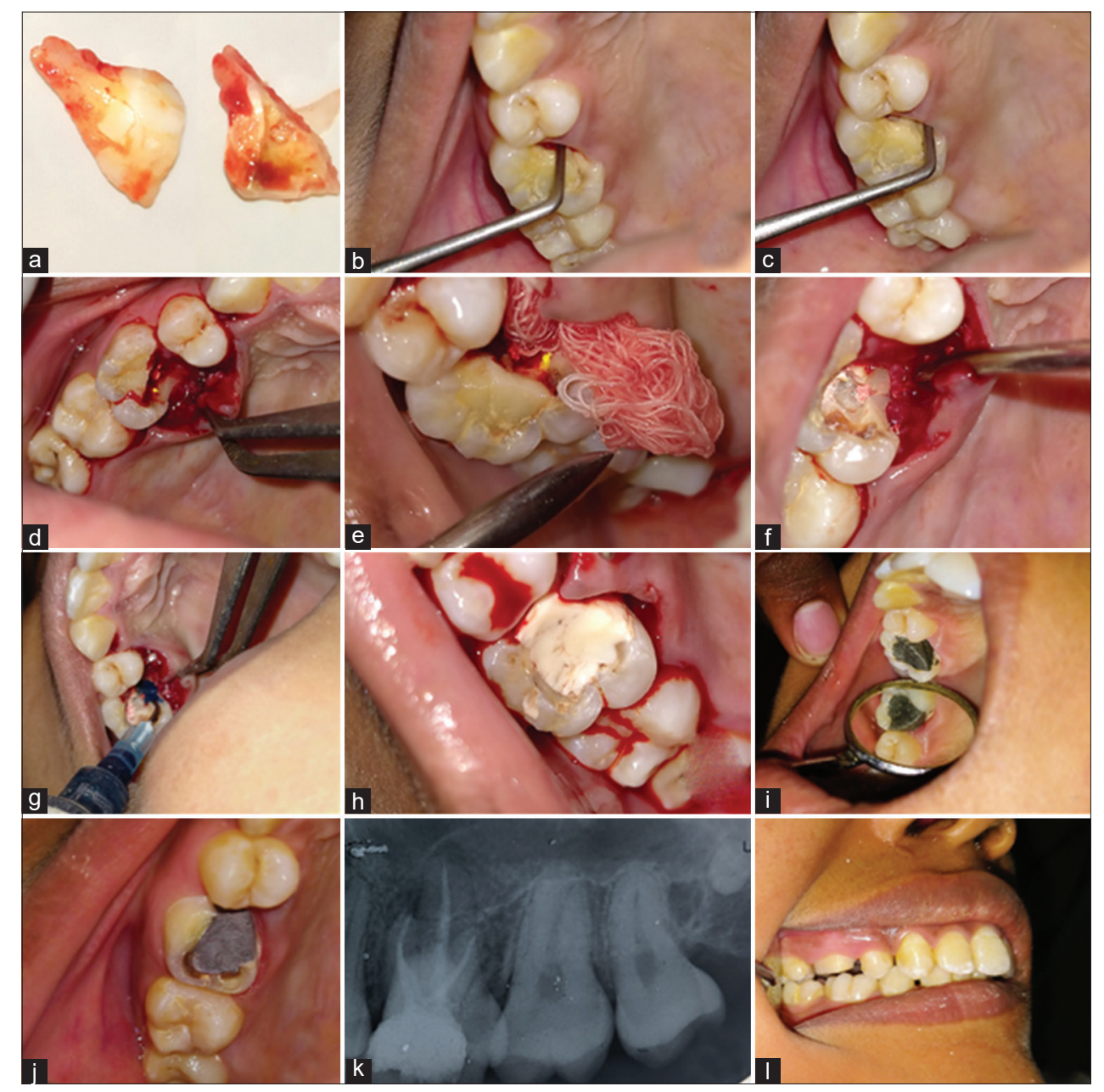

Figure 2: Operative image. (a) Post-removal of fractured part, (b and c) oblique pattern of basal seat, (d) flap elevation, (e and f) local hemostasis with adrenaline gauz, (g) etching, (h) GIC build up, (i and j) miracle mix core build up, (k) postoperative radiograph, and (l) crown preparation 


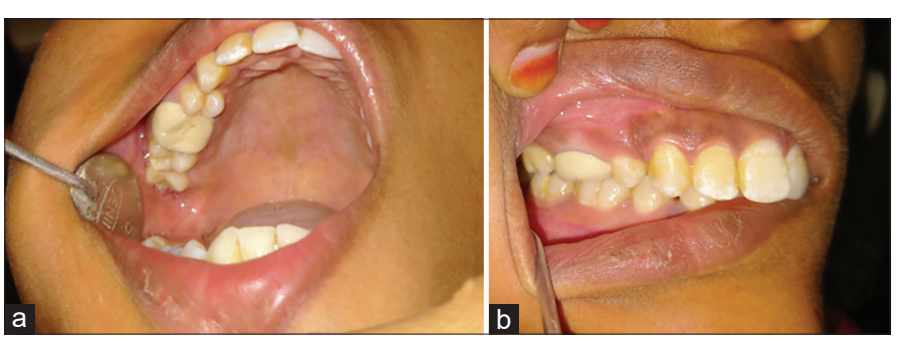

Figure 3: (a and b) Post-operative crown cementation

gingival attachment. The tooth was prepared for the cast crown and a porcelain fused metal-ceramic crown was placed over the tooth for further functional usage (Fig. $2 \mathrm{k}$ and 1). The crown was placed in such a way to minimize the normal occlusal forces over the tooth (Fig. 3a and b). The patient was further followed up for good functional results for a period of 1 year, which satisfies the functional criteria.

\section{DISCUSSION}

Many authors have reported various techniques regarding restoration of endodontically treated tooth, but in this case, the anatomical and operative challenges limited the usage of some literature available steps, and so, the margin was elevated supragingivally for further management with sound knowledge on eliminating all other available sources of management for restoration of this kind of defects.

Endodontically treated permanent coronal restorations should replace interim restorations as soon as possible to prevent the subsequent fracture of the tooth. The modulus of elasticity and the fracture resistance of the teeth might be reduced not only by the loss of hard tooth substance but also by changes in the moisture content of dentin with aging and also with the loss of vital pulp tissue. Increased moisture loss leads to an increased risk for brittle fracture. In addition, the tensile strength of dentin is far lower than the compressive strength which would again severe the incidence of fracture following root canal treatment $[9,10]$. When posterior tooth cusps are weakened, then cuspal coverage with bonded resin composite, amalgam, cast metal alloy, or high strength ceramic materials is mandatory to prevent further tooth fracture [11]. The placement of a well-constructed coronal restoration will have a greater effect on endodontic success than the quality of the endodontic obturation and also appears more important than the type of core/foundation or the post that is employed [12].

An in vitro investigation found that the loss of structural tooth integrity associated with endodontic access preparation might lead to a higher occurrence of fractures in endodontically treated teeth, for which sufficient bulk of tooth structure is required, which is lacking in this case, limiting the use of retentive pins and over the instrumentation of root canals with excessive removal of dentin and the presence of non-circular canals and thin canal walls, particularly with certain tooth types, increase the risk for root fracture [13]. Trope et al. showed that the preparation of the canal and insertion of the post itself weakens the restoration. For these reasons, posts should be used only for the retention of a core within the remaining tooth structure when there are no other alternatives [14]. However, in this case, as there was insufficient support for the retentive pins, their usage was avoided.

Dragoo histologically analyzed hopeless teeth presenting external resorptions. A flap was raised, and the cavity was treated and filled with a GIC. After 1 year, the teeth were extracted. Results showed that the connective tissue was joint to the material, with very few inflammatory cells. A long junctional epithelium and shallow sulcus were found [15]. Based on two randomized clinical trials, Santamaria et al. compared connective tissue grafts on healthy roots and roots treated with GIC at the $6^{\text {th }}$ months and 24 months follow-up. There were no significant differences clinically between both procedures for the percentage of root coverage, pocket depth, and attachment level. Thus, based on clinical observations, it seems that GIC is well tolerated subgingivally. These clinical outcomes were confirmed for the same patient immunologically thorough the analysis of the crevicular fluid composition, the subgingival plaque, its bacteria from red complexes, for the presence of inflammatory markers at 180 days. Polymerase chain reaction analysis failed to show any difference between both groups for any of these factors [16,17]. Hence, the posterior high strength GIC is the choice of the material for the subgingival deep margin restorations in this case report.

Subgingival interdental margin may be encountered when replacing deep class 2 carries. The use of direct adhesive restoration for this does not represent an ideal solution, even when associated with shrinkage stress reduction techniques (slow start curing, flowable liner, and incremental placement) [18]. As the result of post-curing shrinkage that takes place several days after composite resin restoration, the dentin gingival seal will not be secure. Accordingly, due to their size, such defect requires restoration with inlays/onlays using computer-aided design/computer-aided manufacturing [19]. Such cases generate significant technical and operative challenges during the isolation of the operating field using a rubber dam, adhesive procedure, impression taking, and adhesive luting. Or else, it affects the longevity of the restoration. There are various clinical approaches to this challenge [20-22]. The gingiva may be apically displaced; however, this may lead to attachment loss, anatomical complications such as furcation, or root concavities.

Another approach, presented by Dietschiqnd spreafico in 1998 [21], is to place a base of composite resin to coronally displaced proximal margins underneath indirect bonded restorations. This procedure is known as deep margin elevation or coronal margin relocation. It is performed under rubber dam isolation following the placement of the matrix. In addition to the supragingival elevation of the margin, the adhesive composite resin base is used to seal the dentin, reinforce undermined cusps, fill undercuts, and provide the necessary geometry for inlay/ onlay restorations [23]. Here, for the restoration of the defect, the gingival seat lies on the mesiopalatal part of the root structure in the middle-third and on elevating the flap as there exists the operative challenge in isolation with the presence of excessive continuous bleeding and the restorative surface is not favorable 
enough for isolation with the presence of indentations for the oozing blood to flow through continuously. That too, it cannot be stopped at the basal gingival seat area in the radicular segment close to the tissue making it impossible for direct resin-bonded restorations as in deep margin elevation technique. Furthermore, due to its drawback of polymerization shrinkage post restoratively, it is not advisable to employ it in this case of a subgingival defect in the root segment.

\section{CONCLUSION}

A thorough logical understanding of the consequences following the treatment is mandatory for the successful outcomes of the procedure which is not having much literature evidence. This being one such case of grossly destructed tooth involving tooth root of the root canal treated tooth, limiting the usage of retentive pins or post and core and also particular with a selection of proper restorative material based on those biological hindrances for their usage in this particular case but yet planned for functional rehabilitation according to patient willingness without extracting, finally concluded that skilled hands with logical brains matter most for new thoughts being implemented into clinical practice with successful functional outcomes.

\section{REFERENCES}

1. Salehrabi R, Rotstein I. Endodontic treatment outcomes in a large patient population in the USA: An epidemiological study. J Endod 2004;30:846-50.

2. Assif D, Gorfil C. Biomechanical considerations in restoring endodontically treated teeth. J Prosthet Dent 1994;71:565-7.

3. Kishen A. Mechanisms and risk factors for fracture predilection in endodontically treated teeth. Endod Topics 2006;13:57-83.

4. Helfer AR, Melnick S, Schilder H. Determination of the moisture content of vital and pulpless teeth. Oral Surg Oral Med Oral Pathol 1972;34:661-9.

5. Baraban DJ. The restoration of pulpless teeth. Dent Clin North Am 1967;11:633-53.

6. Perel ML, Muroff FI. Clinical criteria for posts and cores. J Prosthet Dent 1972;28:405-11.

7. Trabert KC, Cooney JP. The endodontically treated tooth. Restorative concepts and techniques. Dent Clin North Am 1984;28:923-51.

8. Colman HL. Restoration of endodontically treated teeth. Dent Clin North Am 1979;23:647-62.
9. Lehman ML. Tensile strength of human dentin. J Dent Res 1967;46:197-201.

10. Kinney JH, Nalla RK, Pople JA, Breunig TM, Ritchie RO. Age-related transparent root dentin: Mineral concentration, crystallite size, and mechanical properties. Biomaterials 2005;26:3363-76.

11. $\mathrm{Wu} \mathrm{Y}$, Smales RJ. Identifying and reducing risks for potential fractures in endodontically treated teeth. J Endod 2010;36:609-17.

12. Aquilino SA, Caplan DJ. Relationship between crown placement and the survival of endodontically treated teeth. J Prosthet Dent 2002;87:256-63.

13. Zhi-Yue L, Yu-Xing Z. Effects of post-core design and ferrule on fracture resistance of endodontically treated maxillary central incisors. J Prosthet Dent 2003;89:368-73.

14. Trope M, Maltz DO, Tronstad L. Resistance to fracture of restored endodontically treated teeth. Endod Dent Traumatol 1985;1:108-11.

15. Dragoo MR. Resin-ionomer and hybrid-ionomer cements: Part II, human clinical and histologic wound healing responses in specific periodontal lesions. Int J Periodontics Restor Dent 1997;17:32-5.

16. Santamaria MP, Da Silva Feitosa D, Casati MZ, Nociti FH, Sallum AW, Sallum EA. Randomized controlled clinical trial evaluating connective tissue graft plus resin-modified glass ionomer restoration for the treatment of gingival recession associated with non-carious cervical lesion: 2-year follow-up. J Periodontol 2013;84:e1-8.

17. Santamaria MP, Queiroz LA, Mathias IF, Neves FL, Silveira CA, Bresciani E, et al. Resin composite plus connective tissue graft to treat single maxillary gingival recession associated with non-carious cervical lesion: Randomized clinical trial. J Clin Periodontol 2016;43:461-8.

18. Leung RL, Fan PL, Johnston WM. Post-irradiation polymerization of visible light-activated composite resin. J Dent Res 1983;62:262-5.

19. Magne P, Dietschi D, Holz J. Esthetic restorations for posterior teeth: Practical and clinical considerations. Int $\mathrm{J}$ Periodontics Restor Dent 1996;16:104-19.

20. Dietschi D, Olsburgh S, Krejci I, Davidson C. In vitro evaluation of marginal and internal adaptation after occlusal stressing of indirect class II composite restorations with different resinous bases. Eur J Oral Sci 2003;111:73-80.

21. Dietschi D, Spreafico R. Current clinical concepts for adhesive cementation of tooth-colored posterior restorations. Pract Periodontics Aesthet Dent 1998;10:47-54.

22. Veneziani M. Adhesive restorations in the posterior area with subgingival cervical margins: New classification and differentiated treatment approach. Eur J Esthet Dent 2010;5:50-76.

23. Magne P, Spreafico RC. Deep margin elevation: A paradigm shift. Am J Esthet Dent 2012;2:86-96.

Funding: None; Conflicts of Interest: None Stated.

How to cite this article: Sivakumar S, Meeral PR. Functional rehabilitation of fractured root canal treated posterior tooth: A case report. Indian J Case Reports. 2020;6(10):553-556. 